\title{
A DEFENCE OF THE NEW TENSELESS THEORY OF TIME
}

\section{By L. NATHAN OAKLANDER}

As we ordinarily think and talk about time it is a truism that time passes. Dates, like the events that occur at those dates, are once in the future, then become present, and then recede into the more and more distant past with the passage of time. To think of time as passing, and events as changing with respect to the characteristics of pastness, presentness and futurity, is to conceive of the transient aspect of time or temporal becoming. One central issue in the philosophy of time concerns the metaphysical nature of temporal becoming. Do events exemplify the non-relational properties of pastness, presentness and futurity, as the tensed theory maintains, or are they intrinsically tenseless exemplifying only the unchanging relations of simultaneity, earlier and later, as the tenseless view believes? Although the issue is metaphysical the dispute between the tensed and the tenseless views has, until quite recently, centred around temporal language. Defenders of the tenseless view have often argued that since tensed discourse could be eliminated or translated without loss of meaning into tenseless discourse, an adequate account of the nature of time need not countenance any special kind of tensed fact or tensed properties. In other words, the old tenseless theory of time assumed that a logical analysis of ordinary language that eliminates tensed discourse, supported an ontological analysis of time that rejects transient temporal properties. The tenser shared that assumption, but argued that since no tenseless translations were successful, temporal becoming in some form or another (for example, as the acquiring and shedding of transitory temporal properties, or as the moving NOW), is necessary in any adequate account of time. Tensers claim, in other words, that because tensed discourse is ineliminable, the detenser is mistaken and tensed properties and facts must exist.

For a variety of reasons, some having to do with arguments in the philosophy of time and some having to do with arguments in the philosophy of language, recent defenders of the tenseless view have come to embrace the thesis that tensed sentences cannot be translated by tenseless 
ones without loss of meaning. ${ }^{1}$ Nevertheless, recent detensers have denied that the ineliminability of tensed language and thought entails the reality of temporal properties. According to the new tenseless theory of time, our need to think and talk in tensed terms is perfectly consistent with its being the case that time is timeless. Tensed discourse is indeed necessary for timely action, but tensed facts are not, since the truth conditions of tensed sentences can be expressed in a tenseless metalanguage that describes unchanging temporal relations between and among events.

In a recent article Quentin Smith offers a provocative response to the new tenseless theory of time. ${ }^{2} \mathrm{He}$ argues that since the new tenseless theory is faced with insurmountable problems, it must be either radically reworked or abandoned in favour of the tensed theory. Although he offers numerous arguments in support of these contentions, his central arguments purport to show that the detenser gives a logically inadequate analysis of ordinary temporal discourse and a metaphysically inadequate (because incomplete) account of the truth conditions of tensed sentences. The purpose of this paper is to argue that the tenseless theory of time need not be abandoned or radically reworked (although perhaps it needs to be clarified), since the difficulties Smith raises are indeed surmountable.

Smith launches his attack on the new tenseless theory by criticizing D. H. Mellor's token-reflexive version of it. On Mellor's view the world is intrinsically tenseless in that events and things are not in themselves past, present or future. Of course, we do make judgements (and have beliefs) about the tense of things and such judgements (or beliefs) are sometimes true, but the truth conditions of a tensed sentence or judgement-token can be given in terms of a tenseless and not a tensed fact. On the token-reflexive account that Mellor propounds, the temporal relation between the date at which one says, thinks, or writes down a tensed sentence and the event or thing that it is about, provides an objective basis for the truth-value of any tensed sentence. A present tense sentence token is true if, and only if, it occurs (exists tenselessly) at (roughly) the same time as the event it is about; a past-tense token is true if, and only if, it occurs at a time later than the event it refers to, and so on. Thus, on the token-reflexive account the truth conditions of tensed sentence and judgement-tokens are tenseless facts. ${ }^{3}$

See, for example, Beer (1988); Butterfield (1985); MacBeath (1983); Mellor (1981), chapter 5; Oaklander (1984), chapter IV; and Seddon (1987), chapter 13.

${ }^{2}$ Smith (1987). All page references in the text (from Smith) will be to this article.

${ }^{3}$ See, Mellor (1981), chapter 2. All page references in the text (from Mellor) will to this article. 
Mellor argues that we should not be misled into thinking that tensed discourse is eliminable, translatable, or has the same meaning as tenseless discourse. For a necessary condition of one sentence being the translation of another is that they both have the same truth conditions, but tensed sentences have different truth conditions from tenseless ones (Mellor, pp. 74-8.). At this point, through a judicious selection of quotes, Smith argues that Mellor contradicts himself because he also maintains that tensed sentences have the same truth conditions as the tenseless sentences that state their truth conditions, and thus are translatable in terms of the tenseless ones. Consequently, Smith claims that Mellor's tenseless account of time is internally inconsistent, since he maintains that tensed sentences both do and do not have the same truth conditions as tenseless sentences; and that tensed sentences both are and are not translatable by tenseless ones (Smith, pp. 374-8).

At the outset we may admit that Mellor is not always as clear as he should be and that, therefore, there is some basis in the text for attributing an internal inconsistency to him. Nevertheless, the token-reflexive version of the new tenseless theory of time can avoid the contradiction Smith appears to uncover by distinguishing between sentence-types and sentence-tokens. To see how this distinction helps, let us begin by clarifying it. A sentencetoken is a particular object that exists at a definite time and a definite place. A sentence-type is either the sum of all the tokens of that type or the geometrical property (the shape) that is common to all tokens of that type. As Mellor puts it:

For me, the important feature of tokens as opposed to types is that a token is a particular object, in this case an arrangement of ink on the particular piece of paper you are looking at, i.e. a thing which is in a definite place at every moment of its existence. The sentence type, by contrast, is a much more widespread object than any of its tokens, if indeed it is an object at all. The sentence type you are now reading a token of, for instance, is scattered across the world as widely as - I hope - copies of this book are. Sentence types are in fact not so much objects as properties of objects, namely of all the objects that are their tokens. (p. 35)

Now, consider the sentence type:

(1) It is now 1980

and call it 'S'. What are the truth conditions of $S$ ? In so far as $S$ is construed as a tensed sentence-type it does not strictly speaking have truth 
conditions, only its tokens do. As a consequence, we should also say that, strictly speaking, tensed sentence-types have no truth value. Nevertheless, we can speak of the 'truth conditions' of S in a Pickwickian sense, in which case they will vary from time to time, that is, they will depend on when a token of $S$ is thought or uttered or written down. A sentence-token is uttered' when the words, either written or spoken, of which it is composed, are produced on a given occasion. And, in the case of token-reflexive sentences like $S$, 'is true' and 'is false' apply to sentence-tokens. Thus, a token of S uttered in 1980, call it ' $\mathrm{S}(1980)$ ', is true because it occurs (exists tenselessly) in 1980 whereas another another token of $S$ uttered in 1981, call it ' $\mathrm{S}(1981)$ ', is false because it does not occur in 1980. Clearly, then, 'some tokens of the same tensed type will differ in truth-value depending on their date' (p.100). On the other hand, none of the tokens of the same tenseless type will vary in truth value from time to time. For example, all tokens of ' $S(1980)$ occurs in 1980 ' have the same truth value regardless of the date. ${ }^{4}$ Thus, the truth conditions of (the different tokens of) the sentence types ' $S$ ' and ' $S(1980)$ occurs in 1980' are different, because a token of the tenseless sentence may be true at a time when a token of the tensed sentence is false.

However, if we are considering ' $S$ ' and 'S occurs in 1980' as sentencetokens, then their truth conditions are the same: they are true if, and only if, $S$ occurs in 1980. Smith, on the other hand, interprets Mellor to be saying that

any token of "S occurs in 1980" has different truth conditions than any token $S$ of "It is now 1980" because $S$ is true if it occurs in 1980 and "S occurs in 1980" if true at all is true "at all times" it is tokened. (p. 379)

But this way of putting the point is misleading. If we are talking about a token of ' $S$ occurs in 1980', then it is nonsense to speak of it as being true at all times it is tokened. Tenseless sentence-types are 'true' (or 'false') at all times they are tokened (that is, tokens of a tenseless sentence-type are either all true or all false), but tokens are not themselves tokened at different times. Furthermore, to maintain that $S$ is not true 'at all times' is ambiguous and masks a confusion. If ' $S$ ' stands for a sentence-type, then any token of it is true if it is produced in 1980. But if ' $S$ ' stands for a 1980

\footnotetext{
4 I wrote the sentence-type as ' $\mathrm{S}(1980)$ occurs in 1980 ' because, to be precise, ' $\mathrm{S}$ occurs in 1980 ' does not have all true (or false) tokens. Since ' $S$ ' is the name of a sentence-type, when tokens of S do not occur in 1980, tokens of 'S occurs in 1980' will be false, but when tokens of S do occur in 1980, tokens of ' $S$ occurs in 1980' will be true. In other words, if ' $S$ ' stands for a sentence-type, then the truth value of (the tokens of) both ' $S$ ' and 'S occurs in 1980' will vary from time to time depending on their date.
} 
token of 'It is now 1980', then, like the tenseless sentence that states its truth conditions, $\mathrm{S}$ is true at all times. To quote Mellor once again:

The whole point of the type/token distinction, . . . is that tensed tokens as opposed to types, have definite and temporally unqualified truth values. ... A saying or writing of ' $e$ is past' which occurs before $e$ always was and always will be just plain false. (pp. 99-100)

Thus, it does not follow that tensed sentence-tokens have different truth conditions from the tenseless sentence-tokens which state these truth condition. Smith could only think they were different by confusing sentence-tokens with sentence-types. More importantly, Mellor's version of the token-reflexive theory can be modified to avoid an alleged internal inconsistency. For there is no inconsistency in claiming that tensed and tenseless sentence-types have tokens with different truth conditions, while also claiming that tensed and tenseless sentence tokens themselves have the same truth conditions.

From Smith's point of view, this way out of the contradiction will provide Mellor with little solace. For if tensed tokens have the same truth conditions as tenseless ones, then Mellor's view reduces to the old tenseless theory of time which he explicitly denies. As Smith argues:

Mellor's only ground for holding that tokens of tensed sentences cannot be translated by tokens of tenseless sentences is that these tokens have different truth conditions, and once these truth conditions are seen to be the same, Mellor is deprived of his reasons for subscribing to the thesis of the new theory that tensed tokens are untranslatable. (p. 387; emphasis added)

Smith's reasoning here is not very convincing. In the first place, for Mellor, having the same truth conditions is a necessary but not a sufficient condition for translatability. Thus, even if a tensed and tenseless sentence-token have the same truth conditions, it does not follow that the former can be translated by the latter. Furthermore, it is simply not true that Mellor's only ground for denying the translatability thesis is that tensed and tenseless sentences have different truth conditions. Mellor gives other reasons for denying the translatability thesis. He claims that in order for two sentences to have the same meaning they must have the same use. Now, one of the chief uses of tensed sentences is to tell people what time it is. For example, it is perfectly correct to answer the question, 'When are we going to the movies?' by the retort, 'We are going to the movies now.' On 
the other hand, we cannot use the tenseless sentence 'Our going to the movies is simultaneous with the token "We are going to the movies now", to inform a questioner when we are going to the movies. Hence, Mellor concludes that tensed and tenseless sentence-tokens have different meanings and that is one reason, other than their having different truth conditions, why tokens of tensed sentences cannot be translated by tokens of tenseless sentences (see Mellor, pp. 74-88).

There are other reasons for denying the translatability thesis but we need not pursue them, for on that point recent detensers and tensers both agree. Moreover, the crucial question is not whether or not Mellor's view is internally consistent but rather, whether the token-reflexive version of the new tenseless theory of time is true. And that turns on the following question: 'Do tokens of tensed sentences have only those tenseless truth conditions stated by tokens of tenseless sentences?' Smith argues that they do not since tensed facts must also be introduced, but I shall argue that his arguments fail.

Smith begins his argument against the token-reflexive account of the truth conditions of tensed sentences by noting that:

(1) It is now 1980

entails the sentence

(2) 1980 is present.

In the language of facts this means that there cannot be a fact statable by any token $S$ of $(1)$ unless there is a fact statable by any token $\mathrm{V}$ of (2). In other words, a fact statable by $S$ implies a fact statable by $\mathrm{V}$, and consequently a fact statable by $\mathrm{V}$ is among the truth conditions of S. (p. 379)

Smith then claims that the tenseless truth conditions (or the fact statable by any token $S$ ) of (1), namely, $S$ occurs in 1980, does not entail the tenseless truth conditions (or the fact statable by any token V) of (2), namely, $\mathrm{V}$ occurs in 1980, (for (1) could be true although no token V of (2) is uttered). He concludes, tenseless truth conditions are not sufficient to explain the logical relations between (1) and (2), tensed truth conditions must be introduced for that purpose. Thus, Mellor's token-reflexive version of the tenseless theory fails because

he could not establish that the tenseless facts are the only truth conditions of tensed sentence-tokens; tensed facts need to be 
assumed to account for the entailment-relations between tensed sentences for which Mellor's tenseless truth conditions could not account. ... Mellor's tenseless truth conditions could not explain the logical equivalence of "It is now 1980 " and " 1980 is present", since $S$ occurs in 1980 neither implies nor is implied by $V$ occurs in 1980, (pp. 379-80)

There does indeed appear to be a difficulty here for the token-reflexive analysis. For if one sentence logically implies a second, then we should be able to justify the inference on the basis of truth conditions; we should be able to show that what makes the first true must make the second true. If we cannot do this, there would seem to be grounds for concluding either that we are mistaken about the putative entailment relations or that we have not got the right truth conditions for the sentences in question.

Although Mellor does not directly consider this objection, his most recent pronouncements on time and tense (1988-89) suggest a way out of the difficulty Smith raises. It involves employing Kaplan's (1978) views on demonstratives and indexicals, and arguing that one can thereby account for the logical equivalence of (1) and (2) in terms of tenseless truth conditions. According to Kaplan (and Mellor), the meaning of an indexical sentence-type (and all of its tokens) is a semantic function (rule) from facts about tokens of that type (their context of utterance) to their tenseless truth conditions. In particular, the meaning of (1) and (2) is a semantic function from the context of utterance, namely, the time at which their tokens are produced, to their tenseless truth conditions. Since the context of utterance varies so do the truth conditions of their tokens, but in each case, the truth conditions are tenseless. Thus, any token of (1) is true with respect to the context in which it is produced (namely the time at which it is uttered), if, and only if, the year of that context is 1980 , and the same may be said of any token of (2). Consequently, since the truth conditions of (tokens of) (1) and (2) are the same, the difficulty of getting (1) and (2) to be logically equivalent vanishes. ${ }^{5}$

In the second part of his paper Smith critically examines the 'date-version' of the new tenseless theory of time. Like the token-reflexive account, the date-version of the tenseless theory is not new. Earlier proponents of the tenseless theory such as Russell (1906), Goodman (1966), and Quine (1941)

\footnotetext{
${ }^{5}$ In Oaklander (1990) I propose a different way out of the problem Smith raises for the token-reflexive account.
} 
adopted it. In its old form the date-version of the tenseless view maintained that a sentence in which the word 'now' or its equivalent is used can be translated through the use of a second sentence formed by replacing the 'now' in the first sentence with any date-expression used to refer to the time at which the first sentence was uttered. Consider, for example, Quine's statement of this view:

Logical analysis is facilitated by requiring rather that each statement be true once and for all or false once and for all, independently of time. This can be effected by rendering verbs tenseless and then resorting to explicit chronological descriptions when need arises for distinctions of time. . . . The sentence (1) 'Henry Jones of Lee St., Tulsa, is ill' uttered as a tensed sentence on July 28, 1940, corresponds to the statement 'Henry Jones of Lee St., Tulsa, is [tenseless] ill on July 28, 1940'. (Quine 1941, p.6)

The new date-version denies the thesis of linguistic reducibility and claims instead that corresponding to every tensed sentence-token is a tenseless sentence that gives its truth conditions. For example, Smart claims that:

the notion of becoming present seems a pretty empty notion, and this is even more obvious when we recognize the indexical nature of words like 'present', 'past', and 'future'. When a person P utters at a time $t$ the sentence 'Event $E$ is present' his assertion is true if, and only if, $\mathrm{E}$ is at $\mathrm{t}$. More trivially, when $\mathrm{P}$ says at $\mathrm{t}$ 'time $\mathrm{t}$ is now' his assertion is true if, and only if, $t$ is at $t$ so that if $P$ says at $t$ ' $t$ is now' his assertion is thereby true. (Smart 1981, p. 5)

This view has recently been modified, renamed the Co-reporting Thesis, and defended by Richard Gale (1984) and Michelle Beer (1988). Again, the heart of the co-reporting thesis is that temporal indexicals like 'now', 'this time' and 'the present', as used on a given occasion, are referring terms which denote a time. On this view, if a temporal indexical sentence such as 'Event $\mathrm{E}$ is now occurring' is uttered at $\mathrm{t}_{1}$, then it reports an event that is identical with the event reported at any time by the use of the non-indexical sentence 'Event $\mathrm{E}$ is occurring at $\mathrm{t}_{1}$ '. On this view, indexicals and proper names such as dates are rigid designators. Thus, a tensed sentence like 'It is now 1980' uttered in 1980, reports the same fact as the necessary truth reported by 'It is 1980 in 1980' or ' 1980 is at 1980'. It does not follow, and it is not part of the co-reporting thesis to maintain that 'It is now 1980' and ' 1980 is at 1980' express the same proposition or have the same meaning. On this version of the new tenseless theory of time, as on the other, two 
sentences can have different meanings, while still having the same truth conditions, or corresponding to the same fact.

Smith's main arguments against the date-version of the new tenseless theory of time purport to demonstrate that the truth conditions of tensed sentences are not what the tenseless theory claims to be. He does this by arguing that (i) a 1980 token of 'It is not 1980' is logically contingent; and that (ii) Smart's truth conditions analysis of ' $E$ is present' is mistaken. His first argument in support of (i) is stated as follows:

even if tokens of 'now' are rigid designators, it is false that 1980 tokens of "It is now 1980" are tautologically true.... Now, for any tautologically true sentence-token, the truth of the token is entailed by premises stating the relevant tautological fact and that the token occurs. But

and

(1) 1980 is at 1980 ,

(2) S occurs, do not entail

(3) $S$ is true. (p. 386)

It is not clear to me why (2) alone does not entail (3). Since ' $S$ ' is the name of a 1980 token of 'It is now 1980', premise (2) could also be read as

(2') A 1980 token of 'It is now 1980' occurs

and $\left(2^{\prime}\right)$ does entail (3). Smith might object that (2) cannot be replaced by $\left(2^{\prime}\right)$ because

" $S$ " is a proper name of the sentence token and (if the KripkeDonnellan theory is correct) thereby directly refers to $S$, without imparting any information about it, such that it has the property of occurring in 1980. (p. 387)

I would reply that since ' $S$ ' names a sentence that contains a 1980 token of 'now', (2) can be replaced by $\left(2^{\prime}\right)$, or at least (2) entails $\left(2^{\prime}\right)$, which in turn entails (3).

But suppose that Smith is correct and (3) is not entailed by (1) and (2), so that a 1980 token of 'It is now 1980' is logically contingent. What metaphysical significance does that have? Plenty, according to Smith, for

it shows . . that rigidly designating 1980 is not the only semantic property of ["now"]. That this token in addition imparts some information about 1980 . . . It must also impart the tensed 



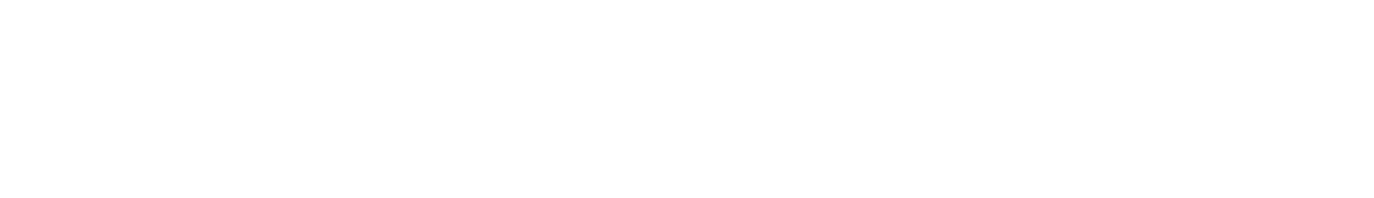

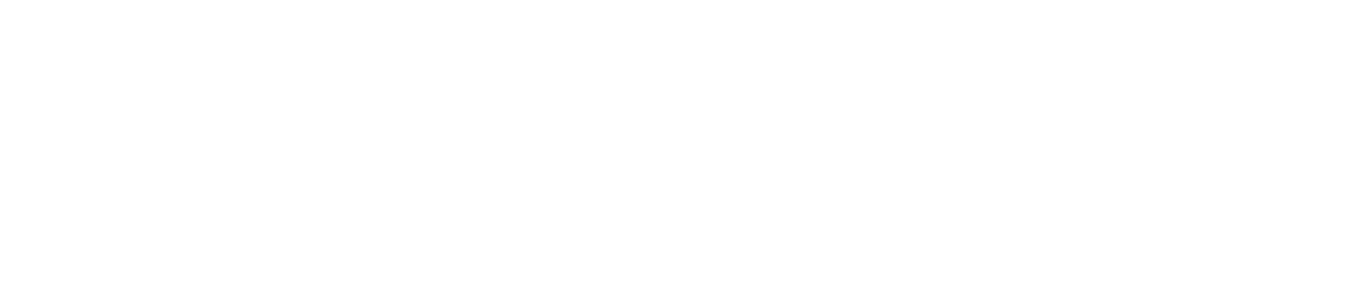


what Smith maintains, the new tenseless theory of time need not be abandoned or radically reworked. ${ }^{6,7}$

The University of Michigan-Flint

\section{REFERENCES}

Beer, M. (1988) 'Temporal Indexicals and the Passage of Time', The Philosophical Quarterly, 38, pp. $158-64$.

Butterfield, J. (1985) 'Indexicals and Tense', in I. Hacking (ed.) Exercises in Analysis (Cambridge: Cambridge University Press), pp. 69-87.

Gale, R.M.: (1984) 'An Identity Theory of the A- and B- Series', Dialectics and Humanism.

Goodman, N. (1966) The Structure of Appearance, (Indianapolis: Bobbs Merrill Co. Inc.).

Kaplan, D. (1978) 'On the Logic of Demonstratives', Fournal of Philosophical Logic, 8, pp. 81-98; repr. in N. Salmon and S. Soames (eds), Propositions and Attitudes, (Oxford: Oxford University Press, 1988), pp. 66-82.

MacBeath, M. (1983) 'Mellor's Emeritus Headache', Ratio 25, pp. 81-8.

Mellor, D.H. (1981) Real Time (Cambridge: Cambridge University Press).

- (1988/89) 'I and Now', Proceedings of the Aristotelian Society, LXXXIX, Pt 2, pp. 79-94.

Oaklander, L.N. (1984) Temporal Relations and Temporal Becoming (Lanham, MD.: University Press of America).

- (1990) 'The New Tenseless Theory of Time: A Reply to Smith', Philosophical Studies, 58, pp. 287-92.

Quine, W.V.O. (1941) Elementary Logic (New York: Ginn and Co.).

Russell, B. (1906) 'Review of Hugh MacColl's Symbolic Logic and its Applications', Mind, 15, pp. 255-60.

Seddon, K. (1987) Time (New York: Croom Helm).

Smart, J.J.C. (1981) 'Time and Becoming', in P. van Inwagen (ed.), Time and Cause (Dordrecht: Reidel), pp. 3-15.

Smith, Q. (1987) 'Problems with the New Tenseless Theory of Time', Philosophical Studies, 52, pp. 371-92.

(1990) 'The Co-reporting Theory of Tensed and Tenseless Sentences', The Philosophical Quarterly, 40, pp. 213-22.

${ }^{6}$ Smith furthers the debate between the new tenseless and the tensed theories in Smith (1990). However, a consideration of his discussion lies beyond the scope of this paper.

${ }^{7}$ I wish to thank Neil Cooper, Hugh Mellor, Quentin Smith and anonymous referees for their useful comments on earlier versions of this paper. I also wish to thank the University of Michigan-Flint for an award that partially funded research for this paper. 
what Smith maintains, the new tenseless theory of time need not be abandoned or radically reworked. ${ }^{6,7}$

The University of Michigan-Flint

\section{REFERENCES}

Beer, M. (1988) 'Temporal Indexicals and the Passage of Time', The Philosophical Quarterly, 38, pp. $158-64$.

Butterfield, J. (1985) 'Indexicals and Tense', in I. Hacking (ed.) Exercises in Analysis (Cambridge: Cambridge University Press), pp. 69-87.

Gale, R.M.: (1984) 'An Identity Theory of the A- and B- Series', Dialectics and Humanism.

Goodman, N. (1966) The Structure of Appearance, (Indianapolis: Bobbs Merrill Co. Inc.).

Kaplan, D. (1978) 'On the Logic of Demonstratives', Fournal of Philosophical Logic, 8, pp. 81-98; repr. in N. Salmon and S. Soames (eds), Propositions and Attitudes, (Oxford: Oxford University Press, 1988), pp. 66-82.

MacBeath, M. (1983) 'Mellor's Emeritus Headache', Ratio 25, pp. 81-8.

Mellor, D.H. (1981) Real Time (Cambridge: Cambridge University Press).

- (1988/89) 'I and Now', Proceedings of the Aristotelian Society, LXXXIX, Pt 2, pp. 79-94.

Oaklander, L.N. (1984) Temporal Relations and Temporal Becoming (Lanham, MD.: University Press of America).

- (1990) 'The New Tenseless Theory of Time: A Reply to Smith', Philosophical Studies, 58, pp. 287-92.

Quine, W.V.O. (1941) Elementary Logic (New York: Ginn and Co.).

Russell, B. (1906) 'Review of Hugh MacColl's Symbolic Logic and its Applications', Mind, 15, pp. 255-60.

Seddon, K. (1987) Time (New York: Croom Helm).

Smart, J.J.C. (1981) 'Time and Becoming', in P. van Inwagen (ed.), Time and Cause (Dordrecht: Reidel), pp. 3-15.

Smith, Q. (1987) 'Problems with the New Tenseless Theory of Time', Philosophical Studies, 52, pp. 371-92.

(1990) 'The Co-reporting Theory of Tensed and Tenseless Sentences', The Philosophical Quarterly, 40, pp. 213-22.

${ }^{6}$ Smith furthers the debate between the new tenseless and the tensed theories in Smith (1990). However, a consideration of his discussion lies beyond the scope of this paper.

${ }^{7}$ I wish to thank Neil Cooper, Hugh Mellor, Quentin Smith and anonymous referees for their useful comments on earlier versions of this paper. I also wish to thank the University of Michigan-Flint for an award that partially funded research for this paper. 